\title{
Management of diabetes and arthritis -A systematic review
}

\author{
Syed Wasif Gillani ${ }^{1}$, Mohi Iqbal Mohammed Abdul ${ }^{1,2}$, Hisham A Zaghloul', Irfan \\ Altaf Ansari ${ }^{3}$, Syed Ata-ur-Rahman ${ }^{1}$, Sadaf Farooqui ${ }^{1}$ \\ ${ }^{1}$ College of Pharmacy, Taibah University, Al-Madinah Munawarah, Saudi Arabia, ${ }^{2}$ College of Pharmacy, University of \\ Philippines, Manila, Philippines, ${ }^{3}$ College of Medicine, Taibah University, Al-Madinah Munawarah, Saudi Arabia
}

*For correspondence: Email: wasifgillani@gmail.com; Tel: +966-538419573

Sent for review: 27 February 2018

Revised accepted: 19 April 2018

\begin{abstract}
Purpose: Diabetes is a metabolic syndrome with reported musculoskeletal effects. This systemic review aimed to identify a relationship between diabetes and arthritis; disease-related risk factors, the effect of diet in disease management and the effect of anti-arthritic drugs on diabetes treatment.

Methods: This study analysed 20 articles identified and selected according to the study criteria. PRISMA guidelines were used for identification and screening of literature. Data search covered several primary databases, including Pubmed, Wiley library, Scopus, Clinical Trial Registry, etc.

Results: The study findings suggest a significant correlation between diabetes and arthritis. Obesity, impaired glucose tolerance (MS components), vascular cell adhesion molecule 1 (VCAM-1) hypertension and dyslipidemia are the most common risk factors leading to disease progression. Omega -3-fatty acid showed no protective effect on disease condition.

Conclusion: The findings indicate that anti-tumor necrosis factor (Tnf)- $\alpha$, disease modifying antirheumatic drugs, and Interleukin receptors antagonist improved the efficacy of diabetic medication and maintained blood sugar levels. However, Tnf- $\alpha$ reduced glucose intolerance, and therefore, its therapeutic use in conjunction with diabetic medications should be limited.
\end{abstract}

Keywords: Diabetes, Arthritis, Risk factors, Diet, Pathogenesis, Disease progression, Medication

\begin{abstract}
This is an Open Access article that uses a funding model which does not charge readers or their institutions for access and distributed under the terms of the Creative Commons Attribution License (http://creativecommons.org/licenses/by/4.0) and the Budapest Open Access Initiative (http://www.budapestopenaccessinitiative.org/read), which permit unrestricted use, distribution, and reproduction in any medium, provided the original work is properly credited.
\end{abstract}

Tropical Journal of Pharmaceutical Research is indexed by Science Citation Index (SciSearch), Scopus, International Pharmaceutical Abstract, Chemical Abstracts, Embase, Index Copernicus, EBSCO, African Index Medicus, JournalSeek, Journal Citation Reports/Science Edition, Directory of Open Access Journals (DOAJ), African Journal Online, Bioline International, Open-J-Gate and Pharmacy Abstracts

\section{INTRODUCTION}

The prevalence and incidence of diabetes mellitus is steadily increasing over past few decades. The global burden of diabetes is 422 million approximately in 2014, then 108 million in 1980 [1]. Diabetes Mellitus (DM) is a metabolic disease which involves many physiological organs and primarily characterized by elevated levels of blood sugar [2]. The disease presented in two forms, type1 DM and type2 DM.
Type 1 diabetes is insulin-dependent diabetes commonly diagnosed among children and young adults. The exact cause for type 1 diabetes is still unknown however it is believed that genetic and environmental factors play vital role in disease development and progression. In contrast autoimmune response on $\beta$-cells of pancreas are responsible for development Type 2 DM. Type 2 diabetes is usually developed among middle aged and older adult population [3]. 


\section{DIABETES AND ARTHRITIS}

The patient with diabetes mellitus suffers with the associated myriad musculoskeletal conditions. Diabetes had reported linked to musculoskeletal changes with symptoms such as joint pain and stiffness and this can severely affect the feet and mobility of the patient. People with diabetes are twice more likely to develop arthritis, indicating strong association between diabetes and arthritis [2]. However, there are many forms of arthritis including osteoarthritis, rheumatoid arthritis, gout and juvenile arthritis, yet with the limited literature it is difficult to establish a relationship with all the forms. The prevalence of arthritis is approximately $52.0 \%$ among adults with diabetes [3].

\section{Type 2 DM and rheumatoid arthritis (RA)}

Rheumatoid arthritis (RA) is a chronic disease characterized by systemic inflammation, persistent synovitis, and the presence of autoantibodies. Elevated Inflammatory mediators were in patients with type 2 diabetes years before the clinical onset of RA, thus suggesting a vital role of diabetes in the pathogenesis of RA. Literature also reported that RA patients' were 50 $\%$ more likely to develop type 2 diabetes as compared with non-RA. Attaining sedentary lifestyle because of RA pain further increases the risk for type 2 diabetes mellitus [7].

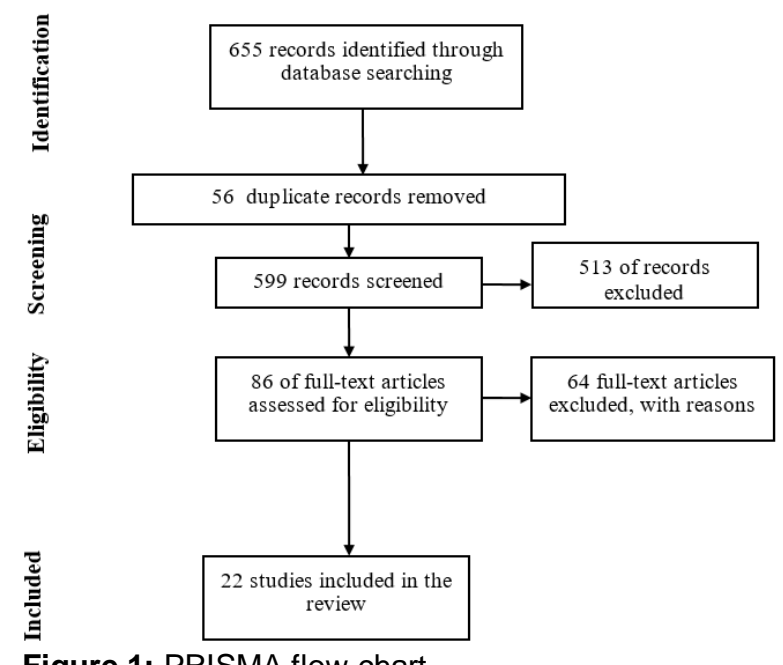

Figure 1: PRISMA flow-chart

\section{Impact of diabetes, obesity and MS on OA}

Osteoarthritis (OA) is the most common type of rheumatic disease and a leading cause of disability among patients. Literature suggested that $>10 \%$ of the world population has confirmed diagnosis of OA. Severe joint pain limits patients' mobility with disease progression. Recently, OA has been recognized as a metabolic disease linked to metabolic syndrome. Evidence also reported the contribution of $O A$ in the development of type 2 diabetes through complex processes involving metabolic syndrome, physical inactivity, and muscle weakness. High frequency of Osteoarthritis among diabetic patients' showed a positive association in-between the diseases [8]. There are several theories suggesting the possible pathogenesis of arthritis in diabetic patients like; a harmful role of excess glucose accumulation through advanced glycation end products (AGEs), oxidative stress and proliferation of systemic inflammation. Risk factors like hypertension, dyslipidemia, pulmonary diseases, depression, psychotic disorders and impaired glucose tolerance are considered factors responsible for the disease development $[9,10]$. Diabetes and Osteoarthritis frequently coexist due to sharing of common risk factors; age, and obesity [11]. Current available literature to establish relationship of arthritis among diabetic population reported contradiction in the conclusions drawn on the effect of diabetes on arthritis and presence of confounding risk factors $\&$ also treatment variability for both diabetes and arthritis. This systematic review managed to reach a consensus on the relationship inbetween arthritis and the diabetes and also addresses the discrepancies in the earlier reports.

\section{Diabetes and gout psoriatic arthritis}

Gout is characterized as extreme arthritis pain and the elevated uric acid blood levels. Particularly in western countries gout is commonly found among middle aged population. Gout also poses a risk for cardiovascular complications including hypertension, obesity, the metabolic syndrome and premature mortality. Higher serum uric acid levels are reported to be a risk factor of diabetes development particularly among women. A study conducted in Canada found higher prevalence of DM in patients with Psoriatic Arthritis [12].

\section{METHODS}

\section{Search subjects}

This study searched the literature on the basis of required criteria as; pathogenesis of arthritis among diabetic patients, the progression rate of arthritis among patient of diabetes and various risk factors associated with it. Complications related to diet \& least mobility in diabetic patients and also its effects on arthritis. Treatment options and related consequences specific to diabetes mellitus only. 


\section{Search eligibility criteria}

This systemic review specifically focused on studies fulfilled the eligibility criteria; published inbetween 2001-2017 and should be written in the English language only. A systematic review and meta-analyses on arthritis among diabetic patients but did not limit our article search to specific type of arthritis. Primarily literature search focused on original research article reported the disease progression and/or development either arthritis-to-diabetes or vice versa.

\section{Search keywords}

Different keywords were used for literature search; 'arthritis', 'type 1 diabetes', type 2 diabetes' 'mobility', 'gout', 'psoriatic arthritis' 'diet', 'treatment options', 'risk factors', 'consequences' and 'complications related to diabetes'.

\section{Primary search}

Different databases and individual journal websites, like Pubmed, Research Gate, Google Scholar, Wiley Online Library, New England Journal of Medicine, Rheumatology, Journal of Medical Case Reports, Clinical Geriatric Medicines, Handbook Experimental Pharmacology, Annals of Rheumology Disorders, Osteoarthritis and Cartilage, Caspian Journal of Internal Medicines and British Medical Journal were used for primary search.

\section{Secondary search}

Once the primary search was completed secondary search was made by using the references of articles that were identified earlier. Primary screening of the articles was mainly focused on the screening of titles and abstracts. Articles that passed through primary screening were critically appraised for the inclusion in the study analysis.

\section{RESULTS AND DISCUSSION}

A total of 22 articles matched the aforementioned criteria and were included for study analysis. Out of 22 studies, 8 studies assessed the association of Arthritis and Diabetes Mellitus and/or glycaemia or Metabolic syndrome (MetS); 5 showed a significant association in their conclusions whereas 3 studies displayed no association. Four studies showed various risk factors, obesity, hypertension, glucose intolerance, vascular cell adhesion molecule-
1(VCAM-1) and dyslipidemia associated with patients suffering from diabetes and arthritis. One study reported no specific effect of diet on either diabetic or arthritis patients'. Nine studies found that the drugs used in the treatment of arthritis like anti-tumor necrosis factor $\alpha$, interleukin-1 receptor antagonists and disease modifying anti-rheumatics were also effective in diabetes management (Table 1 and Table 2).

\section{Metabolic syndrome: a risk factor for osteoarthritis}

MetS is a clustering of risk factors, including dyslipidemia, high blood pressure, impaired glucose tolerance, and abdominal obesity. Hypertension due to subchondral ischemia can cause diminished nutrients exchange into the bone tissues which further trigger bone remodeling leading to $O A$. On the other hand, hyperglycemic conditions, locally cause oxidative stress and the glycation metabolites can cause cartilage damage and systemically glucose accumulation can lead to low-grade systemic inflammation which can exacerbate OA. Obesity also contribute to the etiology of OA particularly due to high adipokines levels $[13,14]$.

\section{Vascular cell adhesion molecule (VCAM-1)}

For the risk of hip and knee joint $O A$, vascular cell adhesion molecule (VCAM-1) is a strong and independent predictor [4]. Increased SVCAM-1 level were found in knee osteoarthritis among type 2 diabetic postmenopausal women in a study also showed inflammation and active cartilage damage. A positive correlation of hyperglycemia with VCAM-1 is present which is consistent with the hypothesis that high intracellular glucose concentration in diabetes promotes the formation of advanced glycation end products. AGE compounds interact with membrane receptors called RAGE present on chondrocytes and give rise to a cascade of events that promote release of pro-inflammatory factors such as TNF- $\alpha$, and activate transcription factors such as Nf-kB, which in turn induces VCAM-1 and promotes inflammation and cartilage degradation [10-12].

Diabetes and arthritis are autoimmune disorders that share obesity and impaired glucose metabolism as risk factor, but may also have relationship through pathogenic mechanisms involving metabolic abnormalities and systemic inflammation [5]. Furthermore, there are pathophysiological evidences linking arthritis and diabetes like age, dyslipidemia and hypertension $[6,7]$. However, the association between Diabetes and arthritis needs to be further 
assessed. This systemic review critically appraised the twenty studies included for analysis. Out of twenty studies, eight studies assessed the association of Arthritis and Diabetes Mellitus; five studies indicated a significant association in their conclusions [8-12]. Three studies displayed no association, they found overweight and inflammation as a cause for arthritis [13-15]. Obesity, hypertension and dyslipidemia and impaired glucose tolerance are major risk factors associated with progression of arthritis (MS components). Two studies found the accumulation of MS components is significantly related to the presence and joint space reduction of knee osteoarthritis [16,17]. In one study comorbid diseases reported to play an important role in predicting survival of primary hip and knee replacements in OA patients [18]. Omega-3-fatty acid had no effect on fasting blood sugar or glycosylated hemoglobin and on pain, swollen joint in arthritis patients' [19].

In summary, most studies found the direct association between diabetes and arthritis. There is a positive association found for risk factors like obesity, hypertension, glucose intolerance, vascular cell adhesion molecule-1 (VCAM-1) and dyslipidemia between diabetes and arthritis. Omega-3-fatty acid had no effect on diabetes and arthritis [10-13]. Different drugs used in the therapy of arthritis helps in reducing the risk of diabetes [10-12]. The relative side effects of these drugs were not found except for anti-tumor necrosis factor $\alpha$ which reported to cause glucose intolerance (Table 3 and Table 4).
There are arthritis drugs which have specific use in diabetes like anti-tumor necrosis factor $\alpha$, interleukin-1 receptor antagonists (bDMARDs) and disease modifying anti-rheumatics (cDMARDs). The use of Anakinra (interleukin-1 receptor antagonist, bDMARDs) showed better glycemic control among diabetic patients in six months [20]. The use of Anti-TNFa (bDMARDs) was associated with $51 \%$ reduction in risk of developing diabetes mellitus. It also causes overall reduction in the risk of type $2 \mathrm{DM}$ and CVD in RA patients [21-24]. With the use of Infliximab (anti-TNF- $\alpha$, bDMARDs) showed dramatic improvement in insulin resistance and sensitivity compare to conventional diseasemodifying anti-rheumatic drugs (cDMARDs) [22].

A long-term positive effect of infliximab and etanercept (bDMARDs) on insulin resistance was also observed in RA patients. Patients with rheumatoid arthritis, use of hydroxychloroquine (cDMARDs) and abatacept (bDMARDS) was positively associated with a reduced risk of diabetes progression [22,23,25]. Hydroxychloroquine (cDMARDs) also optimized glycemic control in type 1 diabetic patient with subtle improvement in the lipid profiling [25].

\section{CONCLUSION}

The relative side effects of anti-rheumatic drugs were not found except for anti-TNF $\alpha$ which causes hypoglycemic attack without warning. Thus further clinical studies are required for finding out side effect of anti-arthritis drug that has specific use in diabetes mellitus.

Table 1: Musculoskeletal effects of diabetes mellitus and association

\begin{tabular}{|c|c|c|}
\hline Conclusion & Article & Summary of findings \\
\hline Positive association & [12] & $\begin{array}{l}\text { Positive association for the musculoskeletal effect in diabetic } \\
\text { patients }\end{array}$ \\
\hline Positive association & [11] & $\begin{array}{l}\text { High frequency of } \mathrm{OA} \text { in patients with } \mathrm{DM} \text { and positive } \\
\text { association between both diseases. }\end{array}$ \\
\hline Positive association & [8] & $\begin{array}{l}\text { Positive association for rheumatoid arthritis patients suffering } \\
\text { from diabetes }\end{array}$ \\
\hline Positive association & [9] & $\begin{array}{l}\text { Positive association for adults with diagnosed DM, nearly halt } \\
\text { also have diagnosed arthritis. }\end{array}$ \\
\hline No association & [14] & RA per se is not associated with increased risk of T2DM \\
\hline Positive association & [10] & $\begin{array}{l}\text { Reports the evidence from clinic and laboratories that DM is } \\
\text { implicated in disease development, severity and outcome for OA. }\end{array}$ \\
\hline No association & [15] & $\begin{array}{l}\text { The association between MetS and radiographic knee OA can be } \\
\text { explained by an excessive weight but not by insulin resistance, } \\
\text { key pathophysiology feature of MetS. }\end{array}$ \\
\hline No association & [13] & $\begin{array}{l}\text { MetS reported to be not significantly linked with hip OA. However } \\
\text { in women, CRP was found to be linked with knee OA, when } \\
\text { adjusted for age. }\end{array}$ \\
\hline
\end{tabular}


Table 2: Progression and association of arthritis among diabetes patients

\begin{tabular}{|c|c|c|c|}
\hline $\begin{array}{l}\text { Various risk factors/Predictors } \\
\text { associated with it }\end{array}$ & Conclusion & Article & Summary of findings \\
\hline $\begin{array}{l}\text { Obesity, hypertension, and } \\
\text { dyslipidemia }\end{array}$ & Positive association & [21] & $\begin{array}{l}\text { Type } 2 \text { DM linked with joint space } \\
\text { reduction in men with knee OA. }\end{array}$ \\
\hline $\begin{array}{l}\text { Overweight, hypertension } \\
\text { dyslipidemia and impaired glucose } \\
\text { tolerance (MS components) }\end{array}$ & Positive association & [16] & $\begin{array}{l}\text { The accumulation of MS components is } \\
\text { significantly related to presence of KOA }\end{array}$ \\
\hline $\begin{array}{l}\text { Vascular cell adhesion molecule } 1 \\
\text { (VCAM-1) }\end{array}$ & Positive association & [4] & $\begin{array}{l}\text { VCAM-1 strongly linked and an } \\
\text { independent predictor of the risk for hip } \\
\text { and knee joint replacement due to OA }\end{array}$ \\
\hline $\begin{array}{l}\text { Cardiovascular diseases, } \\
\text { hypertension, diabetes, cancer, } \\
\text { pulmonary diseases, depression, } \\
\text { psychotic disorders and } \\
\text { neurodegenerative diseases }\end{array}$ & Positive association & [18] & $\begin{array}{l}\text { An important role of co-existing } \\
\text { diseases in predicting survival of } \\
\text { primary hip and knee replacements } \\
\text { emerged. }\end{array}$ \\
\hline
\end{tabular}

Table 3: Complications related to diet and least mobility with diabetes and arthritis

\begin{tabular}{lccl}
\hline Diet & Conclusion & Articles & \multicolumn{1}{c}{ Summary of findings } \\
\hline Omega -3-fatty acid & No association & {$[19]$} & $\begin{array}{l}\text { Omega -3-fatty acid had no effect on fasting } \\
\text { blood sugar or glycosylated hemoglobin and on } \\
\text { pain, swollen joint in arthritis patients }\end{array}$ \\
\hline
\end{tabular}

Table 4: Arthritic drugs and relative effect to diabetes and relative side effects

\begin{tabular}{|c|c|c|c|}
\hline Drug & Use in Diabetes & $\begin{array}{c}\text { Relative side } \\
\text { effect }\end{array}$ & Articles \\
\hline $\begin{array}{l}\text { Anakinra (recombinant non- } \\
\text { glycosylated human interleukin-1 } \\
\text { receptor antagonist) (bDMARDs) }\end{array}$ & Better glycemic control in 6months & ------------ & [20] \\
\hline $\begin{array}{l}\text { Anti-Tumor Necrosis Factor } \alpha . \\
\text { (bDMARDs) }\end{array}$ & $\begin{array}{l}\text { Anti-TNF use was associated with } \\
\text { a } 51 \% \text { reduction in risk of } \\
\text { developing diabetes mellitus. It } \\
\text { also causes overall reduction in the } \\
\text { risk of type } 2 \text { DM and CVD in RA } \\
\text { patients }\end{array}$ & $\begin{array}{l}\text { Unstable DM- } \\
\text { hypoglycemic } \\
\text { attack without } \\
\text { warning. }\end{array}$ & {$[21,23]$} \\
\hline $\begin{array}{l}\text { Disease-Modifying } \\
\text { Anti-rheumatic Drugs } \\
\text { (csDMARDs) \& (bDMARDs) }\end{array}$ & $\begin{array}{l}\text { Patients with RA, the adjusted risk } \\
\text { of DM was lower for individuals } \\
\text { starting a TNF inhibitor or } \\
\text { hydroxychloroquine compared with } \\
\text { the start other non-biologic } \\
\text { DMARDs. }\end{array}$ & ------- & [22] \\
\hline $\begin{array}{l}\text { Hydroxychloroquine (csDMARDs) } \\
\text { and Abatacept (bDMARDs) }\end{array}$ & Helps in decreasing the risk of DM & ----- & [24] \\
\hline Hydroxychloroquine (csDMARDs) & $\begin{array}{l}\text { Patients with rheumatoid arthritis } \\
\text { using hydroxychloroquine reported } \\
\text { to be at less risk to develop } \\
\text { diabetes. }\end{array}$ & --- & [23] \\
\hline Infliximab (anti-TNF- $\alpha$ ) (bDMARDs) & $\begin{array}{l}\text { A long-term positive effect of } \\
\text { infliximab and etanercept on insulin } \\
\text { resistance in RA patients was } \\
\text { noted. }\end{array}$ & --- & [18] \\
\hline $\begin{array}{l}\text { Hydroxychloroquine (HCQ) } \\
\text { (csDMARDs) }\end{array}$ & $\begin{array}{l}\text { Glycemic control was optimized } \\
\text { with the introduction of HCQ as } \\
\text { treatment for type } 1 \text { diabetes. }\end{array}$ & ---- & [17] \\
\hline
\end{tabular}

\section{DECLARATIONS}

\section{Acknowledgement}

We acknowledge the contribution of Associate Prof. Dr. Hassaan Anwar Rathore for language editing and provide valuable comments on manuscript contents.

\section{Conflict of interest}

No conflict of interest is associated with this work. 


\section{Authors' contribution}

We declare that this work was done by the authors named in this article and all liabilities pertaining to claims relating to the content of this article will be borne by the authors. SWG \& MIMA: Principal investigator and drafted the manuscript. HAZ \& IAA: Content analysis. SAUR \& SF: Literature search and revised manuscript. All authors read and approved the final manuscript.

\section{REFERENCES}

1. Food and Drug Administration/Center for Drug Evaluation and Research. Guidance for industry: waiver of in vivo bioavailability and bioequivalence studies for immediate release solid oral dosage forms based on a biopharmaceutics classification system. 2000.

2. What do diabetes and arthritis have in common? Plenty. Arthritis foundation 2017 15th May. Available from: http://www.arthritis.org/living-witharthritis/comorbidities/diabetes-and-arthritis/.

3. Centers for Disease C, Prevention. Arthritis as a potential barrier to physical activity among adults with diabetes-United States, 2005 and 2007. MMWR Morb Mortal Wkly Rep. 2008; 57(18): 486-489.

4. Schett G, Kiechl S, Bonora E, Zwerina J, Mayr A, Axmann $R$, Weger $S$, Oberhollenzer $F$, Lorenzini $R$, Willeit J. Vascular cell adhesion molecule 1 as a predictor of severe osteoarthritis of the hip and knee joints. Arthritis Rheum. 2009; 60(8): 2381-2389.

5. Puenpatom RA, Victor TW. Increased prevalence of metabolic syndrome in individuals with osteoarthritis: an analysis of NHANES III data. Postgrad Med. 2009; 121(6): 9-20.

6. Velasquez MT, Katz JD. Osteoarthritis: another component of metabolic syndrome? Metab Syndr Relat Disord. 2010; 8(4): 295-305.

7. Zhuo $Q$, Yang W, Chen J, Wang Y. Metabolic syndrome meets osteoarthritis. Nat Rev Rheumatol. 2012; 8(12): 729-737.

8. Al-Bishri J, Attar S, Bassuni N, Al-Nofaiey Y, Qutbuddeen H, Al-Harthi S, Subahi S. Comorbidity profile among patients with rheumatoid arthritis and the impact on prescriptions trend. Clin Med Insights Arthritis Musculoskelet Disord. 2013; 6: 11-18.

9. Cheng YJ, Imperatore G, Caspersen CJ, Gregg EW, Albright AL, Helmick CG. Prevalence of diagnosed arthritis and arthritis-attributable activity limitation among adults with and without diagnosed diabetes: United States, 2008-2010. Diabetes Care. 2012; 35(8): 16861691.

10. King KB, Rosenthal AK. The adverse effects of diabetes on osteoarthritis: update on clinical evidence and molecular mechanisms. Osteoarthritis Cartilage. 2015; 23(6): 841-850.
11. Louati K, Vidal C, Berenbaum F, Sellam J. Association between diabetes mellitus and osteoarthritis: systematic literature review and meta-analysis. RMD Open. 2015; 1(1): e000077.

12. Wyatt LH, Ferrance RJ. The musculoskeletal effects of diabetes mellitus. J Can Chiropr Assoc. 2006; 50(1): 4350.

13. Engstrom G, Gerhardsson de Verdier M, Rollof J, Nilsson $P M$, Lohmander LS. C-reactive protein, metabolic syndrome and incidence of severe hip and knee osteoarthritis. A population-based cohort study. Osteoarthritis Cartilage. 2009; 17(2): 168-173.

14. Laires P, Fonseca JE, Garcia EB. PMS55 Analysis on the Possible Association between Rheumatoid Arthiritis and Diabetes Mellitus Type 2. Value in Health; 13(7): A313.

15. Shin D. Association between metabolic syndrome, radiographic knee osteoarthritis, and intensity of knee pain: results of a national survey. J Clin Endocrinol Metab. 2014; 99(9): 3177-3183.

16. Yoshimura N, Muraki S, Oka H, Kawaguchi H, Nakamura $K$, Akune T. Association of knee osteoarthritis with the accumulation of metabolic risk factors such as overweight, hypertension, dyslipidemia, and impaired glucose tolerance in Japanese men and women: the ROAD study. J Rheumatol. 2011; 38(5): 921-930.

17. Eymard F, Parsons C, Edwards MH, Petit-Dop F, Reginster JY, Bruyere $O$, Richette $P$, Cooper $C$, Chevalier $X$. Diabetes is a risk factor for knee osteoarthritis progression. Osteoarthritis Cartilage. 2015; 23(6): 851-859.

18. Jamsen E, Peltola M, Eskelinen A, Lehto MU. Comorbid diseases as predictors of survival of primary total hip and knee replacements: a nationwide register-based study of 96754 operations on patients with primary osteoarthritis. Ann Rheum Dis. 2013; 72(12): 19751982.

19. MacLean CH, Mojica WA, Morton SC, Pencharz J, Hasenfeld Garland R, Tu W, Newberry SJ, Jungvig LK, Grossman J, Khanna $P$, et al. Effects of omega-3 fatty acids on lipids and glycemic control in type II diabetes and the metabolic syndrome and on inflammatory bowel disease, rheumatoid arthritis, renal disease, systemic lupus erythematosus, and osteoporosis. Evid Rep Technol Assess (Summ). 2004; (89): 1-4.

20. Vitale A, Cantarini L, Rigante D, Bardelli M, Galeazzi M. Anakinra treatment in patients with gout and type 2 diabetes. Clin Rheumatol. 2015; 34(5): 981-984.

21. Antohe JL, Bili A, Sartorius JA, Kirchner HL, Morris SJ, Dancea S, Wasko MC. Diabetes mellitus risk in rheumatoid arthritis: reduced incidence with anti-tumor necrosis factor alpha therapy. Arthritis Care Res (Hoboken). 2012; 64(2): 215-221.

22. Solomon DH, Massarotti E, Garg R, Liu J, Canning C, Schneeweiss $S$. Association between disease-modifying antirheumatic drugs and diabetes risk in patients with rheumatoid arthritis and psoriasis. JAMA. 2011; 305(24): 2525-2531. 
23. Wasko MC, Hubert HB, Lingala VB, Elliott JR, Luggen $M E$, Fries JF, Ward MM. Hydroxychloroquine and risk of diabetes in patients with rheumatoid arthritis. JAMA. 2007; 298(2): 187-193.

24. Boulton JG, Bourne JT. Unstable diabetes in a patient receiving anti-TNF-alpha for rheumatoid arthritis. Rheumatology (Oxford). 2007; 46(1): 178-179.
25. Ozen G, Pedro S, Holmqvist ME, Avery M, Wolfe F, Michaud K. Risk of diabetes mellitus associated with disease-modifying anti-rheumatic drugs and statins in rheumatoid arthritis. Ann Rheum Dis. 2017; 76(5): 848854. 